\title{
Variation in morphological traits of Drosophila melanogaster (fruit fly) under nutritional stress
}

\author{
ALEXANDRA G. IMASHEVA*, DMITRI V. BOSENKO \& OLEG A. BUBLI \\ Vavilov Institute of General Genetics, Gubkin Str. 3, Moscow 117809, Russia
}

\begin{abstract}
The effect of nutritional stress on phenotypical and genetic variation was examined for five morphological traits (thorax length, wing length, sternopleural chaeta number, abdominal chaeta number and arista branch number) in 30 isofemale lines of Drosophila melanogaster. Phenotypical variation of all traits except sternopleural chaeta number and fluctuating asymmetry of all bilateral traits were significantly higher in flies reared under poor feeding conditions. Estimates of isofemale line heritability (coefficients of intraclass correlation) did not show a consistent pattern among traits. However, additive genetic variance was generally higher in poor feeding conditions in all traits except sternopleural chaeta number, although these differences were not statistically significant. Similarly, estimates of evolvability were higher under nutritional stress for all traits except sternopleural chaeta number. These results suggest that nutritional stress increases the expression of genetic variation for some morphological traits in Drosophila and, in this respect, is similar to the effects of temperature stress studied previously.
\end{abstract}

Keywords: Drosophila melanogaster, evolvability, fluctuating asymmetry, genetic variation, morphological traits, stress.

\section{Introduction}

Evolutionary response to selection depends on the amount of genetic variation expressed in the population. Because of this, the effect of environmental changes on the expression of genetic variation in quantitative traits has important evolutionary implications. If genetic variation is inflated in harsh environments, this will result in acceleration of genetic response and, thus, in an increase in the evolutionary rate. If, on the contrary, genetic variation is decreased in such environments, then the selection response in them will be lower than under normal conditions. In the first case, traits will evolve faster in poor habitats; in the second, in the optimal ones.

There is ample evidence indicating that the expression of genetic variation in fact changes with changing environment (Hoffmann \& Parsons 1991, 1997a). The direction of this change is still unclear. In animals, most stressful factors are believed to increase genetic variation (Hoffmann \& Parsons,

*Correspondence. E-mail: sasha@vigg.ru.
1991, 1997a; and references therein). However, this is not always the case. In a recent study on the collared flycatcher (Merilä, 1997), the nutritional stress was shown to decrease the additive genetic variation and heritability of tarsus length, a trait related to body size. On the basis of these results and of his review of other studies on avian species, the author argued that genetic variation of body size traits in birds tends to be lower under poor environmental conditions if these conditions imply deficiency in nutrition (food-supplemented vs. deprived broods; reduced vs. enlarged broods; 'good' vs. 'poor' years, etc.).

Based on this and other work (Van Noordwijk et al., 1988; Larsson, 1993), Hoffmann \& Parsons (1997b) made a tentative conclusion that, although some types of stress such as temperature and desiccation, generally increase genetic variation, poor nutrition, in contrast, decreases it and is unusual in this respect. However, in a more recent study, Merilä \& Fry (1998) did not find a decrease in additive genetic variation of body size of blue tits in poor feeding conditions. Moreover, all studies cited by Merilä (1997) and Hoffmann \& Parsons (1997b) 
were restricted to bird species. In view of this, it seems of interest to test the effect of stressful food deficiency on genetic variation in other organisms.

The aim of the present study was to assess the effect of nutritional stress on the expression of phenotypical and genetic variation of morphological traits in Drosophila melanogaster and to compare it with the effects of another type of stress, exposure to extreme temperatures, which was studied previously (Imasheva et al., 1997, 1998). To estimate additive genetic variation, the coefficient of intraclass correlation was used as a measure of heritability (Hoffmann \& Parsons, 1988) and evolvability (Houle, 1992) of the traits.

\section{Materials and methods}

Drosophila melanogaster was sampled in a natural population at Khristinovka, Ukraine, in August 1997. Flies were collected over a fruit bait in a commercial orchard. Immediately after collection, 30 isofemale lines were set up and maintained in the laboratory for 2 months (four generations) before the beginning of the experiment. Each generation was started with approximately $30-40$ pairs of parents placed on fresh medium for several hours to oviposit. The lines were maintained at $25^{\circ} \mathrm{C}$ throughout the experiment.

The standard Drosophila medium used in our experiment contained $70 \mathrm{~g}$ of dry yeast, $17 \mathrm{~g}$ of sugar, $7 \mathrm{~g}$ of agar, $40 \mathrm{~g}$ of ground raisins and $35 \mathrm{~g}$ of semolina per $1 \mathrm{~L}$ of water. Standard medium was supplemented with live yeast. The medium referred to hereafter as poor contained $15 \mathrm{~g}$ of dry yeast, $17 \mathrm{~g}$ of sugar and $7 \mathrm{~g}$ of agar per $1 \mathrm{~L}$ of water. Preliminary experiments showed that egg-to-adult viability of flies reared on poor medium decreased approximately twofold compared with flies reared on standard medium. To both types of medium, $0.5 \mathrm{~mL} \mathrm{~L}^{-1}$ propionic acid was added to prevent moulding. Vials, $2.5 \times 10 \mathrm{~cm}$ in size, containing $10 \mathrm{~mL}$ of medium were used.

To start the experiment, six sets of 20 pairs of newly emerged flies from each isofemale line were placed separately in vials with fresh medium and aged for 6 days, being transferred to fresh yeastseeded medium every second day. On the sixth day, three randomly chosen sets were placed on standard medium, and the remaining three sets were placed on poor medium. They were allowed to deposit eggs for $24 \mathrm{~h}$ and then discarded. First-instar larvae were transferred to vials with fresh medium (20 and 30 larvae per vial in the case of standard and poor medium respectively). After the beginning of emer- gence, flies were sexed and counted each day until the emergence ended. All females from each vial were pooled and placed into fixative liquid (1/2 glycerine:1/2 $70 \%$ ethanol). From each vial, three females were chosen randomly for measurements.

Five morphological traits were scored: thorax length, wing length, number of sternopleural chaetae, number of abdominal chaetae and number of arista branches. Of these, the first two are metric, and the remaining three meristic.

Wing length was measured as the length of the longitudinal vein L3 from the intersection with the anterior crossvein to the tip of the wing. Thorax length was measured from the interior margin of the thorax to the posterior tip of the scutellum (from the dorsal view). Measurement of the metric traits was conducted using an ocular micrometer in arbitrary micrometer units $(70$ units $=1 \mathrm{~mm})$ and converted into $\mathrm{mm} \times 100$.

Bilateral traits (wing length, sternopleural chaeta number and arista branch number) were measured on both sides of the fly. For all statistical analyses except estimation of fluctuating asymmetry, lefthand measurements were used.

Fluctuating asymmetry (FA) was estimated as the absolute difference between the right and left sides standardized by the mean (Palmer \& Strobeck, 1986). Viability was estimated as the proportion of emerging flies to the total number of first-instar larvae transferred into the vial.

All statistical analyses were performed with the STATISTICA package (StatSoft, 1996). As measurements of morphological traits showed no significant deviations from normality in the KolmogorovSmirnov test for goodness of fit and as there are restrictions on transformations for estimating evolvabilities (Houle, 1992), no transformation was used for these traits. Viability estimates were arcsine transformed before ANOVA. Means, variances and coefficients of variation (CVs) of the traits were compared using the $t$-test, the variance ratio test and the Z-test respectively (Sokal \& Rohlf, 1995; Zar, 1996). Confidence limits for the coefficient of intraclass correlation were calculated using the Z-transformation (Zar, 1996).

\section{Results}

Table 1 presents means and estimates of phenotypical variation (variances and CVs) for the five morphological traits of flies reared on the standard and poor media. Only variance in sternopleural chaeta number did not exhibit significant differences between media. For the four other traits examined, 
Table 1 Means, phenotypical variances $s^{2}$, and coefficients of variation CV $(\times 100)$ of morphological traits of Drosophila melanogaster reared on standard and poor media

\begin{tabular}{|c|c|c|c|c|c|c|c|c|c|}
\hline \multirow[b]{2}{*}{ Trait $\uparrow$} & \multicolumn{3}{|c|}{ Standard medium } & \multicolumn{3}{|c|}{ Poor medium } & \multicolumn{3}{|c|}{ Comparison: standard vs. poor } \\
\hline & Mean \pm SE & $s^{2}$ & $\mathrm{CV} \pm \mathrm{SE}$ & Mean \pm SE & $s^{2}$ & $\mathrm{CV} \pm \mathrm{SE}$ & Mean $(t)$ & $s^{2}(F)$ & $\mathrm{CV}(Z)$ \\
\hline TL & $117.04 \pm 0.19$ & 9.42 & $2.62 \pm 0.11$ & $88.66 \pm 0.42$ & 47.25 & $7.75 \pm 0.34$ & $61.95 * * *$ & $5.02 * * *$ & $14.57^{* * *}$ \\
\hline WL & $158.05 \pm 0.21$ & 11.89 & $2.18 \pm 0.09$ & $132.59 \pm 0.60$ & 96.16 & $7.40 \pm 0.32$ & $40.25 * * *$ & $8.09^{* * *}$ & $15.72 * * *$ \\
\hline $\mathrm{SCN}$ & $9.77 \pm 0.08$ & 1.60 & $12.94 \pm 0.57$ & $8.69 \pm 0.08$ & 1.72 & $15.08 \pm 0.66$ & $9.76^{* * *}$ & 1.07 & $2.50^{*}$ \\
\hline $\mathrm{ACN}$ & $16.61 \pm 0.12$ & 4.11 & $12.20 \pm 0.53$ & $15.37 \pm 0.15$ & 5.74 & $15.58 \pm 0.69$ & $6.52 * * *$ & $1.40^{* *}$ & $3.94 * * *$ \\
\hline ABN & $9.56 \pm 0.04$ & 0.46 & $7.12 \pm 0.31$ & $9.24 \pm 0.05$ & 0.71 & $9.12 \pm 0.40$ & $4.89^{* * *}$ & $1.53^{* * *}$ & $4.02 * * *$ \\
\hline
\end{tabular}

$\dagger$ Here and in further tables: TL, thorax length; WL, wing length; SCN, sternopleural chaeta number; ACN, abdominal chaeta number; $\mathrm{ABN}$, arista branch number.

$\S$ Test statistics used for comparison are given in parentheses.

$* P<0.05 ; * * P<0.01 ; * * * P<0.001$.

both variances and CVs were significantly higher in flies reared on poor medium $(P<0.001$ for all traits except variance in abdominal chaeta number, for which $P<0.01$ and $\mathrm{CV}$ in sternopleural chaeta number, for which $P<0.05$ ).

In Table 2, fluctuating asymmetry (FA) values for three bilateral traits (wing length, sternopleural chaeta number and arista branch number) are compared in flies reared on standard vs. poor medium. For all of the traits, differences in FA between media are statistically significant $(P<0.001$ for wing length and sternopleural chaeta number, $P<0.01$ for abdominal chaeta number).

Two-way ANOvA of the traits (Table 3) showed that the line effect was significant in all of them $(P<0.001$ except arista branch number, which had $P<0.01)$, but the vial effect was non-significant.

In Table 4, estimates of different measures of genetic variation for each trait in flies reared on standard and poor media are presented. These are the between-line variance, $V_{\mathrm{B}}$, which is half the additive genetic variance $\left(V_{\mathrm{A}}=2 V_{\mathrm{B}}\right)$ (Falconer, 1989), the coefficient of intraclass correlation, which

Table 2 Fluctuating asymmetry of morphological traits in Drosophila melanogaster reared on standard and poor media

\begin{tabular}{lcrc}
\hline Trait & $\begin{array}{c}\text { Standard } \\
\text { medium }\end{array}$ & \multicolumn{1}{c}{$\begin{array}{c}\text { Poor } \\
\text { medium }\end{array}$} & $\begin{array}{c}\text { Significance } \\
\text { of differences }(t) \dagger\end{array}$ \\
\hline WL & $0.53 \pm 0.04$ & $1.22 \pm 0.07$ & $8.23^{* * *}$ \\
SCN & $6.23 \pm 0.40$ & $10.55 \pm 0.61$ & $5.92^{* * *}$ \\
ABN & $4.42 \pm 0.40$ & $6.18 \pm 0.41$ & $4.89^{* *}$ \\
\hline
\end{tabular}

$\dagger$ d.f. $=538$.

${ }^{* *} P<0.01 ;{ }^{* * *} P<0.001$.

(C) The Genetical Society of Great Britain, Heredity, 82, 187-192. measures the proportion of the additive genetic component in the total variance, and Houle's evolvability, which is the additive genetic variance standardized by the squared mean (Houle, 1992). Note that the estimates of these genetic measures were obtained using the isofemale line method. Consequently, they cannot be precise as the degree of relatedness among isofemale lines is unknown. However, this is not of prime importance for the purposes of this study, because the aim was to compare the effects of different environments on the same lines.

For four of the traits, the between-line variances were generally higher when flies were reared on poor medium. These differences were not statistically significant because of the large standard errors of the estimates. The exception was the number of sternopleural chaeta, for which phenotypical variances also did not differ between media (see Table 1 ). As for the coefficients of intraclass correlation, the direction of differences between media was not consistent among traits: the values of this parameter were higher for the poor medium for thorax length, arista branch number and abdominal chaeta number, but lower for wing length and sternopleural chaeta number. These differences were not statistically significant except for wing length $(P<0.05)$. Evolvabilities were generally higher for flies reared on the poor media in all cases except maybe sternopleural chaeta number. The greatest $(\approx 15$-fold $)$ difference was recorded for thorax length; for wing length, it was about fourfold, and twofold for both arista branch number and abdominal chaeta number. The Wilcoxon paired-sample test (Zar, 1996) for comparison of means did not show a significant difference between standard and poor media in additive genetic variance $(Z=1.75, P=0.080)$, 
Table 3 Two-way AnOva of morphological traits for 30 isofemale lines of Drosophila melanogaster

\begin{tabular}{|c|c|c|c|c|c|c|}
\hline \multirow[b]{2}{*}{ Trait } & \multirow[b]{2}{*}{ Source } & \multirow[b]{2}{*}{ d.f. } & \multicolumn{2}{|c|}{ Standard medium } & \multicolumn{2}{|c|}{ Poor medium } \\
\hline & & & MS & $F$ & MS & $F$ \\
\hline \multirow[t]{3}{*}{$\mathrm{TL}$} & Line & 29 & 0.23 & $2.63^{* * *}$ & 1.44 & $3.57 * * *$ \\
\hline & Vial & 60 & 0.09 & 1.15 & 0.41 & 1.19 \\
\hline & Error & 180 & 0.08 & & 0.34 & \\
\hline \multirow[t]{3}{*}{ WL } & Line & 29 & 0.67 & $14.81 * * *$ & 2.67 & $3.72 * * *$ \\
\hline & Vial & 60 & 0.05 & 0.84 & 0.69 & 0.87 \\
\hline & Error & 180 & 0.05 & & 0.79 & \\
\hline \multirow[t]{3}{*}{$\mathrm{SCN}$} & Line & 29 & 5.56 & $4.29 * * *$ & 5.33 & $3.93 * * *$ \\
\hline & Vial & 60 & 1.30 & 1.22 & 1.36 & 1.08 \\
\hline & Error & 180 & 1.06 & & 1.26 & \\
\hline \multirow[t]{3}{*}{$\mathrm{ACN}$} & Line & 29 & 11.91 & $4.59 * * *$ & 20.45 & $5.48 * * *$ \\
\hline & Vial & 60 & 2.60 & 0.77 & 3.73 & 0.92 \\
\hline & Error & 180 & 3.36 & & 4.03 & \\
\hline \multirow[t]{3}{*}{$\mathrm{ABN}$} & Line & 29 & 0.98 & $2.29 * *$ & 1.68 & $2.86^{* * *}$ \\
\hline & Vial & 60 & 0.43 & 1.08 & 0.59 & 0.99 \\
\hline & Error & 180 & 0.39 & & 0.59 & \\
\hline
\end{tabular}

$* * P<0.01 ; * * * P<0.001$.

but the difference was significant for evolvability estimates $(Z=2.02, P=0.043)$.

In addition to morphological traits, viability (percentage of emerged flies) was measured, which can serve as a measure of severity of stress. Mean viabilities were $0.94 \pm 0.01$ on standard and $0.40 \pm 0.02$ on poor medium; the difference between these values is highly significant $(P<0.001)$. The one-way ANOVA (Table 5) showed that between-line

Table 4 Between-line components of variance $V_{\mathrm{B}}$, coefficients of intraclass correlation $r_{\mathrm{i}}$ with their lower $\left(L_{1}\right)$ and upper $\left(L_{2}\right)$ confidence limits and evolvabilities $\left(I_{\mathrm{A}}\right)$ of morphological traits in isofemale lines of Drosophila melanogaster reared on standard and poor media

\begin{tabular}{llrcccc}
\hline Trait & Medium & \multicolumn{1}{c}{$V_{\mathrm{B}}$} & $r_{\mathrm{i}}$ & $L_{1}$ & $L_{2}$ & $I_{\mathrm{A}} \times 100$ \\
\hline TL & Standard & 1.669 & 0.181 & 0.073 & 0.319 & 0.024 \\
& Poor & 12.088 & 0.254 & 0.129 & 0.403 & 0.307 \\
WL & Standard & 6.912 & 0.570 & 0.415 & 0.706 & 0.055 \\
& Poor & 20.000 & 0.215 & 0.099 & 0.359 & 0.228 \\
SCN & Standard & 0.494 & 0.306 & 0.171 & 0.460 & 1.035 \\
& Poor & 0.450 & 0.260 & 0.134 & 0.410 & 1.191 \\
ACN & Standard & 0.972 & 0.224 & 0.106 & 0.370 & 0.704 \\
& Poor & 1.833 & 0.308 & 0.172 & 0.460 & 1.552 \\
ABN & Standard & 0.064 & 0.138 & 0.042 & 0.265 & 0.140 \\
& Poor & 0.121 & 0.175 & 0.069 & 0.312 & 0.284 \\
\hline
\end{tabular}

variance of viability was significantly different from zero. The values of between-line genetic variance, $V_{\mathrm{B}}$, were 0.010 on standard and 0.070 on poor medium; the coefficients of intraclass correlation for viability were 0.291 for standard and 0.509 for poor medium. Although these differences are not significant, the trend is for higher additive genetic variation on poor in relation to standard medium.

\section{Discussion}

Judging from the viability estimates, the nutritional stress used in our experiment was severe, as it caused mortality of more than half of the population. This stress resulted in a significant increase in phenotypical variation of each morphological trait examined except sternopleural chaeta number. In a

Table 5 One-way ANOvA of viability in 30 lines of Drosophila melanogaster reared on standard and poor media

\begin{tabular}{lcccccc}
\hline & & \multicolumn{2}{c}{ Standard } & & \multicolumn{2}{c}{ Poor } \\
\cline { 3 - 4 } \cline { 5 - 6 } Source & d.f. & $\mathrm{MS} \times 10^{3}$ & $F$ & & $\mathrm{MS} \times 10^{3}$ & $F$ \\
\hline Line & 29 & 55.16 & $2.23^{* *}$ & & 26.30 & $4.11^{* * * *}$ \\
Error & 60 & 24.74 & - & & 6.40 & - \\
\hline
\end{tabular}

${ }^{*} P<0.01 ; * * * P<0.001$.

(C) The Genetical Society of Great Britain, Heredity, 82, 187-192. 
similar manner, fluctuating asymmetry of all bilateral traits studied increased significantly, which indicated an increase in the amount of 'developmental noise' under this type of stress.

These results are not unexpected as, in our previous work, in which the effect of rearing $D$. melanogaster at extreme temperatures on essentially the same set of morphological traits was examined, the temperature stress consistently resulted in a significant increase in phenotypical variation and FA (Imasheva et al., 1997, 1998).

The present results indicate that at least two types of environmental stress factors - extreme temperatures and poor nutrition - consistently increase the phenotypical variation and FA of morphological traits in D. melanogaster. Further experiments are needed to find out whether this rule holds for other types of stress.

The situation with the effect of nutritional stress on genetic variation is less clear-cut. The additive genetic variation in four out of five morphological traits examined generally increased in poor growth conditions, although this increase was not statistically significant. The measure conventionally used to estimate the proportion of additive genetic variation in the total variation in the isofemale line technique is coefficient of intraclass correlation, which is proportional to narrow-sense heritability and has been termed isofemale heritability (Hoffmann \& Parsons, 1988). This parameter did not exhibit a consistent pattern of change under nutritional stress: in two traits, it increased under stress; in another two, the opposite trend was observed and, in one trait (sternopleural chaeta number), no changes under stress were found.

As the narrow-sense heritability is the ratio of additive genetic variance to the total variance, changes in it may result from changes in additive genetic variance, residual variance, which measures variation attributable to non-additive genetic and environmental causes, or both. Because of this, as noted by Houle (1992), evolutionary implications can hardly be drawn from changes in heritability estimates alone. To overcome this difficulty, Houle suggested another measure of the ability of a population to respond to selection, which he termed evolvability (Houle, 1992). In evolvability, additive genetic variance is standardized by the mean of the trait rather than by its variance. Consequently, in this measure, confounding effects of changes in environmental or non-additive genetic components of variation are eliminated. In our experiment, the evolvability estimates of all traits were generally higher under nutritional stress; however, no statisti- cal comparisons can be made, as Houle (1992) does not give the expression for the standard error of this estimate. Note that, as in Houle's study, size-related traits under normal conditions had lower evolvabilities than meristic ones, but the former were far more strongly affected by exposure to stress.

There is evidence that temperature stress also increases genetic variation in morphological traits of Drosophila. Using the isofemale line technique, Barker \& Krebs (1995) compared the heritabilities of thorax length, wing length and their ratio in two related Drosophila species, D. aldrichi and D. buzzatii, reared at $18^{\circ} \mathrm{C}, 24^{\circ} \mathrm{C}$ and $31^{\circ} \mathrm{C}$. They concluded that genetic variation for body size traits in these species was generally higher when reared at less favourable temperatures. In $D$. melanogaster, temperature extremes $\left(12^{\circ} \mathrm{C}\right.$ and $\left.31^{\circ} \mathrm{C}\right)$ have been shown to increase both additive genetic variance and isofemale heritabilities for thorax length, sternopleural chaeta number (both extreme temperatures) and wing length (low temperature) (Imasheva et al., 1998). In contrast to these results, Sgrò \& Hoffmann [cited in Jenkins et al. (1997)], comparing genetic variance of wing length in parents and their firstgeneration offspring subjected to the same or different temperatures, did not find any effect of temperature extremes on the expression of genetic variation in $D$. melanogaster. However, in the range of temperatures they used $\left(14^{\circ} \mathrm{C}, 25^{\circ} \mathrm{C}\right.$ and $\left.28^{\circ} \mathrm{C}\right)$, only one $\left(14^{\circ} \mathrm{C}\right)$ can be considered stressful. This fact can, at least partly, account for the failure to find temperature effects on genetic variation.

The lack of consistent effects of stress temperatures on genetic variation of quantitative traits reported in some other studies (Murphy et al., 1983; Gebhardt \& Stearns, 1988, 1992) may have the same explanation as, in all of these cases, no temperature extremes were applied and thus no stress in the strict sense, i.e. severe impairment of fitness, was obtained.

Our results indicate that, in D. melanogaster, poor nutrition is similar with regard to its effects on phenotypical and genetic variation to temperature stress. Both of these factors, at levels that are close to lethality, increase heritable variation of morphological traits related to size, and thus enhance the evolutionary potential of populations and their ability to be changed by selection.

\section{Acknow ledgements}

We thank anonymous reviewers for valuable comments on the manuscript and Oleg Lazebny and Tatyana Rakitskaya for help in transferring larvae. 


\section{References}

BARKER, J. S. F. AND KREBS, R. A. 1995. Genetic variation and plasticity of thorax length and wing length in Drosophila aldrichi and Drosophila buzzatii. J. Evol. Biol., 8, 689-709.

FALCONER, D. C. 1989. Introduction to Quantitative Genetics, 3rd edn. John Wiley, New York.

GEBHARDT, M. D. AND STEARNS, S. C. 1988. Reaction norms for developmental time and weight at eclosion in Drosophila mercatorum. J. Evol. Biol., 1, 335-354.

GEBHARDT, M. D. AND STEARns, S. C. 1992. Phenotypic plasticity for life-history characters in Drosophila melanogaster. III. Effect of the environment on genetic parameters. Genet. Res., 60, 87-101.

HOFFMANN, A. A. AND PARSONS, P. A. 1988. The analysis of quantitative variation in natural populations with isofemale strains. Génét. Sél. Évol., 20, 87-98.

HOFFMANN, A. A. AND PARSONS, P. A. 1991. Evolutionary Genetics and Environmental Stress. Oxford University Press, Oxford.

HOFFMANN, A. A. AND PARSONS, P. A. 1997a. Extreme Environmental Change and Evolution. Cambridge University Press, Cambridge.

HOFFMANN, A. A. AND PARSONS, P. A. 1997b. Consistent heritability changes under poor growth conditions. Trends Ecol. Evol., 12, 460-461.

HOULE, D. 1992. Comparing evolvability and variability of quantitative traits. Genetics, 130, 195-204.

IMASHEVA, A. G., LOESCHCKE, V., ZHIVOTOVSKY, L. A. AND LAZEBNY, O. E. 1997. Effects of extreme temperatures on phenotypic variation and developmental stability in Drosophila melanogaster and D. buzzatii. Biol. J. Linn. Soc., 61, 117-126.

IMASHEVA, A. G., LOESCHCKE, V., ZHIVOTOVSKY, L. A. AND LAZEBNY, O. E. 1998. Stress temperatures and quantita- tive variation in Drosophila melanogaster. Heredity, 81, $246-253$

JENKINS, N. L., SGRÒ, C. M. AND HOFFMANN, A. A. 1997. Environmental stress and the expression of genetic variation. In: Bijsma, R. And Loeschcke, V. (eds) Environmental Stress, Adaptation and Evolution, pp. 79-96. Birkhäuser, Basle.

LARSSON, K. 1993. Inheritance of body size in the barnacle goose under different environmental conditions. J. Evol. Biol., 6, 195-208.

MERILÄ, J. 1997. Expression of genetic variation in body size of the collared flycatcher under different environmental conditions. Evolution, 51, 526-536.

MERILÄ, J. AND FRY, J. D. 1998. Genetic variation and causes of genotype-environment interaction in the body size of blue tit (Parus caeruleus). Genetics, 148, 1233-1244.

Murphy, P. A., GIESEl, J. T. AND MANLOVE, M. N. 1983. Temperature effects on life-history variation in Drosophila simulans. Evolution, 37, 1181-1192.

PAlMER, A. R. AND STROBECK, c. 1986. Fluctuating asymmetry: measurement, analysis, patterns. Ann. Rev. Ecol. Syst., 17, 391-421.

SOKAL, R. R. AND ROHLF, F. J. 1995. Biometry, 3rd edn. Freeman, New York.

StAtsoft. 1996. Statistica for Windows. Statsoft Inc., Tulsa, OK.

VAN NOORDWIJK, A. J., VAN BALEN, J. H. AND SCHARLOO, W. 1988. Heritability of body size in a natural population of the great tit (Parus major) and its relation to age and environmental conditions during growth. Genet. Res., 51, 149-162.

ZAR, J. H. 1996. Biostatistical Analysis, 3rd edn. Prentice Hall, Upper Saddle River, NJ. 